This document was prepared in conjunction with work accomplished under Contract No. DE-AC09-96SR18500 with the U. S. Department of Energy.

\title{
DISCLAIMER
}

This report was prepared as an account of work sponsored by an agency of the United States Government. Neither the United States Government nor any agency thereof, nor any of their employees, nor any of their contractors, subcontractors or their employees, makes any warranty, express or implied, or assumes any legal liability or responsibility for the accuracy, completeness, or any third party's use or the results of such use of any information, apparatus, product, or process disclosed, or represents that its use would not infringe privately owned rights. Reference herein to any specific commercial product, process, or service by trade name, trademark, manufacturer, or otherwise, does not necessarily constitute or imply its endorsement, recommendation, or favoring by the United States Government or any agency thereof or its contractors or subcontractors. The views and opinions of authors expressed herein do not necessarily state or reflect those of the United States Government or any agency thereof. 


\title{
Using Ant Communities for Rapid Assessment of Terrestrial Ecosystem Health
}

\author{
L. D. Wike \\ F. D. Martin
}

Approved by:

J. B. Gladden 


\section{Using Ant Communities for Rapid Assessment of Terrestrial Ecosystem Health}

Measurement of ecosystem health is a very important but often difficult and sometimes fractious topic for applied ecologists. It is important because it can provide information about effects of various external influences like chemical, nuclear, and physical disturbance, and invasive species. Ecosystem health is also a measure of the rate or trajectory of degradation or recovery of systems that are currently suffering impact or those where restoration or remediation have taken place. Further, ecosystem health is the single best indicator of the quality of long term environmental stewardship because it not only provides a baseline condition, but also the means for future comparison and evaluation. Ecosystem health is difficult to measure because there are a nearly infinite number of variables and uncertainty as to which suites of variables are truly indicative of ecosystem condition. It would be impossible and prohibitively expensive to measure all those variables, or even all the ones that were certain to be valid indicators. Measurement of ecosystem health can also be a fractious topic for applied ecologists because there are a myriad of opinions as to which variables are the most important, most easily measured, most robust, and so forth. What is required is an integrative means of evaluating ecosystem health.

All ecosystems are dynamic and undergo change either stochastically, intrinsically, or in response to external influences. The basic assumption about change induced by exogenous antropogenic influences is that it is directional and measurable. Historically measurements of surrogate parameters have been used in an attempt to quantify these changes, for example extensive water chemistry data in aquatic systems. This was the case until the 1980's when the Index of Biotic Integrity (IBI) (Karr et al. 1986), was developed.

This system collects an array of metrics and fish community data within a stream ecosystem and develops a score or rating for the relative health of the ecosystem. The IBI, though originally for Midwestern streams, has been successfully adapted to other ecoregions and taxa (macroivertebrates, Lombard and Goldstein, 2004) and has become an important tool for scientists and regulatory agencies alike in determining health of stream ecosystems. The IBI is a specific type of a larger group of methods and procedures referred to as Rapid Bioassessment (RBA). These protocols have the advantage of directly measuring the organisms affected by system perturbations, thus providing an integrated evaluation of system health because the organisms themselves integrate all aspects of their environment and its condition. In addition to the IBI, the RBA concept has also been applied to seep wetlands (Paller et al. 2005) and terrestrial systems (O'Connell et al. 1998, Kremen et al. 1993, Rodriguez et al. 1998, Rosenberg et al. 1986). Terrestrial RBA methods have lagged somewhat behind those for aquatic systems because terrestrial systems are less distinctly defined and seem to have a less universal distribution of an all-inclusive taxon, such as fish in the IBI, upon which to base an RBA.

In the last decade, primarily in Australia, extensive development of an RBA using ant communities has shown great promise. Ants have the same advantage for terrestrial RBAs that fish do for aquatic systems in that they are an essential and ubiquitous component of virtually all terrestrial ecosystems. They occupy a broad range of niches, functional groups, and trophic levels and they possess one very important characteristic that makes them ideal for RBA because, similar to the fishes, there is a wide range of tolerance to conditions within the larger taxa. Within ant communities there are certain groups, genera, or species that may be very robust and abundant under even the harshest impacts. There are also taxa that are very sensitive to disturbance and change and their presence or absence is also indicative of the local conditions. Also, as with the aquatic RBAs using macroinvertebrates, ants have a wide variety of functional foraging or feeding groups, by whose abundance or scarcity an evaluation of the system health may be made. Much of the ground work has been done for useful ant RBAs, but it has primarily been in Australia, Europe, the US desert Southwest, and South America (Australia; Majer and Nichols, 1998, Anderson, 1991, Read, 1996, Lobry de Bruyn, 1999, Majer et al. 1984, Majer 1985, Anderson, 1997, Oliver and Beattie, 1996: Europe; Puszkar, 1978, Gomez et al. 2003: South America; Bestelmeyer and Weins, 1996, Majer, 1992, Kalif et al. 2001, Osborn et al. 1999, Estrada M. and Fernandez C. 1998: SW US and Mexico; Kaspari and Majer, 2000). However, the work already done will transport well to other ecoregions and as has been done with the IBI, it could be adapted with an appropriate investment of time and resources. It would be necessary to establish taxonomic expertise, allocate the local ant fauna to functional groups, and evaluation and modification of metrics and characteristics used to develop indicies 
in the existing methods. Successful adaptation and application of an ant RBA would provide a cost effective, useful, and robust tool for evaluating the health of terrestrial ecosystems anywhere in the region.

\section{Technical Background Information}

1. Rapid bioassessment in general has advantages over other methods to evaluate ecosystem change or health. The primary advantage is that RBAs, by looking at actual communities or functional groups constitute a direct measure of integrated ecosystem health rather than using physical or chemical parameters as surrogates (Barbour et al. 1999). This is true because organisms integrate all parameters within their local immediate habitat, including those that are not obvious or are even unmeasurable at the human scale. In addition, RBA's are a proven concept and have been applied to numerous ecosystems all over the world (Barbour et al. 1999) and are known to be adaptable to regions outside of the area where they were first developed (Paller et al. 1996). Another distinct advantage of RBA techniques is that they can be applied quickly and require minimum laboratory time and equipment so they are therefore exceptionally cost effective.

2. Ant communities are highly responsive to human impact (Folgarait, 1998) and other changes, and even slight modifications to their ecosystem will produce changes in the ant community (Majer, 1983; Andersen, 1997a). These changes can reflect direction and rate of specific impacts, and ants provide a reliable indicator of general change (Andersen, 1997; King et al. 1998). In addition to ecosystem health, restoration, or recovery, ant communities have shown strong correlation to other variables. These variables include total and perennial plant cover (Seymour and Dean, 2002), vegetation type (Burbidge et al. 1992), litter and soil temperature, litter humidity, and forest stand structure (Eltz and Bruhl, 2001), soil faunal richness (Touyama et al. 2002), microclimate (Torres, 1984), and soil, agricultural management, and crop variables (Peck et al. 1998). Finally, ants are widely adopted as indicator organisms as a tool in land management (Andersen and Majer, 2004)

3. Sampling procedures for ants are relatively inexpensive. Pitfall traps, either baited or unbaited, require little effort and resources and so are the most frequently used sampling method (Romero and Jaffe, 1989; Greenslade and Greenslade, 1971; Majer, 1978; Andersen, 1991; Delabie et al. 2000; Greenslade, 1973; Olson, 1991) However, a second method such as litter sifting (Olson, 1991), visual search and hand capture (Romeo and Jaffe, 1989) or other methods (Delabie et al. 2000) found genera and species which were not captured by pitfalls so that pitfalls should be supplemented with at least one other sampling technique.

4. While taxonomy of ants is somewhat complex, all ants are members of family Formicidae within the order Hymenoptera. Living ants are comprised of 11 subfamilies, 297 genera, and approximately 8800 species, with new species being described frequently (Holldobler and Wilson, 1990). However, with only a few hours of training, technicians had identification error rates of less than $13 \%$ which rapidly reduce further with experience (Oliver and Beattie, 1992). It has been found that using functional groups, genera and morphospecies make identification to species generally unnecessary for using ants as indicators of ecosystem health (Andersen and Majer, 2004; King et al, 1998)

According to Andersen and Majer (2004) ants are routinely used in diverse land-use situations in Australia, where their experience has been that the monitoring can be greatly simplified without losing its effectiveness. Because of the usefulness of simplified protocols ants can be easily and economically incorporated into environmental monitoring programs. Rapid bioassessment using ant communities can be developed and tested at SRS and regional military bases. Initial work will develop a working regional inventory of ant species and an assessment of sampling procedures as to effectiveness in including most species and all foraging guilds. Based on the species inventory, appropriate identification procedures will be developed. The next step will be adapting the actual assessment protocols to Southeastern ant communities and developing base line data from undisturbed habitats and habitats that have known histories of recovery. The final test of the concept would involve implementation at a wide range of habitat types of varying degrees of disturbance; excellent opportunities for this are available at several near-by military facilities. Investment in the development of an ant RBA will provide significant savings of time 
and money in future commitments and requirements for environmental impact evaluation and monitoring, restoration necessity and effectiveness, and long term stewardship issues.

\section{$\underline{\text { References }}$}

Andersen, A.N. 1991. Sampling communities of ground-foraging ants: pitfall catches compared with quadrat counts in an Australian tropical savanna. Australian Journal of Ecology 16:273-279.

Andersen, A.N. 1991. Responses of ground-foraging ant communities to three experimental fire regimes in a savanna forest of tropical Australia. Biotropica 23:575-585.

Andersen, A.N. 1995. A classification of Australian ant communities, based on functional groups which parallel plant life-forms in relation to stress and disturbance. Journal of Biogeography 22:12-29.

Andersen, A. 1997. Ants as indicators of ecosystem restoration following mining: a functional group approach. Pp. 319-325. In Hale, P. and D. Lamb (eds.) Conservation outside nature reserves. Centre for Conservation Ecology, The University of Queensland.

Andersen, A. N. 1997a. Using ants as bioindicators: multiscale issues in ant community ecology. Conservation Ecology (online) 1(1):8.

Andersen, A. N., J. D. Majer. 2004. Ants show the way down under: invertebrates as bioindicators in land management. Front. Ecol. Environ; 2(6): 291-298.

Barbour, M.T., J. Gerritsen, B.D. Snyder, J.B. Stribling. 1999. Rapid bioassessment protocols for use in streams and wadeable rivers: periphyton, benthic macroinvertebrates, and fish. Second edition. U.S. Environmental Protection Agency, EPA 841-D-99-002. Washington, D.C.

Bestelmeyer, B. and J.A. Wiens. 1996. The effects of land use on the structure of ground-foraging ant communities in the Argentine Chaco. Ecological Applications 6:1225-1240.

Burbidge, A. H., K. Leicester, S. McDavitt, and J. D. Majer. 1992. Ants as indicators of disturbance at Yanchep National Park, Western Australia. J. Royal Soc W. Australia, 75: 89-95.

Delabie, J.H.C, B.L. Fisher, J.D. Majer and I.W. Wright. 2000. Sampling effort and choice of methods. Pp. 145-154 In Agosti, D. et al. (eds.) Ants: Standard methods for measuring and monitoring biodiversity. Washington, DC: Smithsonian Press.

Eltz, T., and C. Bruhl. 2001. Ecological evaluation of forest management using leaf-litter ants and stingless bees as indicators. Deutsche Gesellschraft fur Technische Zusammenarbeit (GTZ), Eschborn, Germany.

Estrada M., C. and F. Fernández C. 1999 Diversidad de hormigas (Hymenoptera: Formicidae) en un gradiente sucesional del bosque nublado (Nariño, Colombia). Revista de Biología Tropical 47:189-201.

Folgarait, P. J. 1998. Ant biodiversity and its relationship to ecosystem functioning: a review. Biodiversity and Conservation 7, 1221-1244.

Gómez, C., D. Casellas, J. Oliveras, and J.M. Bas. 2003. Structure of ground-foraging ant assemblages in relation to land-use change in the northwestern Mediterranean region. Biodiversity and Conservation 12:2135-2146. 
Greenslade, P. and P.J.M. Greenslade. 1971. The use of baits and preservatives in pitfall traps. Journal of the Australian Entomological Society 10:253-260.

Greenslade, P.J.M. 1973. Sampling ants with pitfall traps: digging-in effects. Insectes Sociaux (Paris) 20:343-353.

Kalif, K.A.B., C. Azevedo-Ramos, P. Moutinho, and S.A.O. Malcher. 2001. The effect of logging on the ground-foraging ant community in eastern Amazonia. Studies on Neotropical Fauna and Environment 36:215-219.

Karr, J. R., K. D. Fausch, P. L. Angermeier, and J. J. Schlosser. 1986. Assessing biological integrity in running water - A method and its rational. Champaign, Ill., Illinois Natural History, Special Publication 5, 28p.

Kaspari, M. and J.D. Majer. 2000. Using ants to monitor environmental change. Pp. 89-98. 154 In Agosti, D. et al. (eds.) Ants: Standard methods for measuring and monitoring biodiversity. Washington, DC: Smithsonian Press.

Kremen, C., R. K. Colwell, T. L. Erwin, D.D. Murphy, R. F. Noss, and M. A. Sanjayan. 1993. Terrestrial arthropod assemblages: their use in conservation planning. Conservation Biology 7:796-808.

King, J. R. A. N. Andersen, A. D. Cutter. 1998. Ants as bioindicators of habitat disturbance: validation of the functional group model for Australia's humid tropics. Biodiversity and Conservation 7:16271638 .

Lobry de Bruyn, L.A. 1999. Ants as bioindicators of soil function in rural environments. Agriculture Ecosystems and Environment 74:425-441.

Lombard, P. J., and R. M. Goldstein. 2004. Freshwater vital signs monitoring plan for National Parks in the Northeast Temperate Network (NETN). Phase II. Selection of water quality monitoring variables. Administrative Report prepared for National Park Service by U.S. Geological Survey, Augusta, Maine, 55p.

Majer, J.D. 1978. An improved pitfall trap for sampling ants and other epigaeic invertebrates. Journal of the Australian Entomological Society 17:261-262.

Majer, J.D. 1983. Ants: Bio-indicators of minesite rehabilitation, land-use, and land conservation. Environmental management, V7,4:375-383.

Majer, J.D. 1985. Recolonization by ants of rehabilitated mineral sand mines on North Stradbroke Island, Queensland, with particular reference to seed removal. Australian Journal of Ecology 10:31-48.

Majer, J.D. 1992. Ant recolonisation of rehabilitated bauxite mines of Poços de Caldas, Brazil. Journal of Tropical Ecology 8:97-108.

Majer, J.D., J.E. Day, E.D. Kabay and W.S. Perriman. 1984. Recolonization by ants in bauxite mines rehabilitated by a number of different methods. Journal of Applied Ecology 21:355-375.

Majer, J.D. and O.G. Nichols. 1998. Long-term recolonization patterns of ants in Western Australian rehabilitated bauxite mines with reference to their use as indicators of restoration success. Journal of Applied Ecology 35:161-182.

O’Connell, T. J., L. E. Jackson, and R. P. Brooks. 1998. The bird community index: a tool for assessing biotic integrity in the Mid-Atlantic Highlands. Final Report. Rept. No. 98-4, Penn State Cooperative Wetlands Center, Pennsylvania State University, 70 pp. 
Oliver, I. and A.J. Beattie. 1993. A possible method for the rapid assessment of biodiversity. Conservatoin Buiology 7:562-568.

Oliver, I. and A.J. Beattie. 1996. Designing a cost-effective invertebrate survey: a test of methods for rapid assessment of biodiversity. Ecological Applications 6:594-607.

Olson, D.M. 1991. A comparison of the efficiency of litter sifting and pitfall traps for sampling leaf litter ants in a tropical wet forest, Costa Rica. Biotropica 23:166-172.

Osborn, F., W. Goitia, M. Cabrera and K. Jaffé. 1999. Ants, plants and butterflies as diversity indicators: comparisons between strata in six Neotropical forest sites. Studies of Neotropical Fauna and Environment 34:59-64.

Paller, M.H., M.J.M. Reichert, and J.M. Dean. 1996. The use of fish communities to assess environmental impacts in South Carolina coastal plain streams. Transactions of the American Fisheries Society 125:633-644.

Peck, S. L., B. McQuaid, and C. L. Campbell. 1998. Using ant species (Hymenoptera, Pormicidae) as a biological indicator of agroecosystem condition. Environmental Entomology 27(5).

Puszkar, T. 1978. Les fourmis (Formicidae) de la zone polluée des établissements de l'azote de Puławy. Memorabilia Zoologica 29:129-142.

Read, J.L. 1996. Use of ants to monitor environmental impacts of salt spray from a mine in arid Australia. Biodiversity and Conservation 5:1533-1543.

Rodriguez, J. P., D. L. Pearson, and R. Barrera R. 1998. A test for the adequacy of bioindicator taxa: Are tiger beetles (Coleoptera:Cicindellidae) appropriate indicators for monitoring the degradation of tropical forests in Venezuela? Biological Conservation 83:69-76.

Romero, H. and K. Jaffe. 1989. A comparison of methods for sampling ants (Hymenoptera, Formicidae) in savannas. Biotropica 21:348-352.

Rosenberg, D. M., H. V. Danks, and D. M. Lehmkuhl. 1986. Importance of insects in environmental impact assessment. Environmental Mangement 10:773-783.

Seymour, C. L., and W. R. J. Dean. 2002. Effects of heavy grazing on invertebrate assemblages in the Succlent Karoo, South Africa. J of Arid Environments, v43(3): 267-286.

Torres, J. A. 1984. Diversity and distribution of ant communities in Puerto Rico. Biotropica 16(4): 296303.

Touyama, Y., T. Yamamoto, and N. Nakagoshi. 2002. Are ants useful bioindicator? - the relationship between ant species richness and soil macrofaunal richness, in Hiroshima Prefecture. Edaphologia No. 70: 33-36. 